\title{
MODELING AND SIMULATION OF THE PROCESS OF PRECIPITATION AND DISSOLUTION OF THE MINERALS CALCITE AND DOLOMITE
}

\author{
B. ELY ${ }^{1}$, A. L. DE BORTOLI ${ }^{1,2}$ \\ ${ }^{1}$ Federal University of Rio Grande do Sul, Graduate Program in Chemical Engineering \\ ${ }^{2}$ Federal University of Rio Grande do Sul, Graduate Program in Applied Mathematics \\ barbara.ely@ufrgs.br, dbortoli@mat.ufrgs.br
}

\begin{abstract}
This work aims to model and simulate the fluid flow in a porous medium with precipitation and dissolution of minerals. The importance of this theme is its contribution to understanding the flow process in the soil, including minerals deposition and aquifers formation. Due to temperature changes, the natural convection of the fluid in the porous medium may induce to precipitation or dissolution of chemical species by changing the $\mathrm{pH}$. There appear many physical phenomena, which can be analyzed by sophisticated transport models. In this work, the model is based on a set of nonlinear differential equations of Navier-Stokes type that considers variations in temperature, pressure, fluid composition and mineral composition. The solution procedure is based on the finite differences Runge-Kutta multistage scheme. The results compare favourably with data found in the literature.
\end{abstract}

\section{INTRODUCTION}

The great interest in predicting the effects of a fluid in a porous medium is its wide application in many areas, among them are the geophysical problems and the quality of groundwater. The slow convective circulation within the sedimentary layer of the soil, as well as the instant heating of the cooling fluid, produces areas of intense transformation. Other factors such as $\mathrm{pH}$ changes and the structure also influence the reaction rate of dissolution and precipitation (Bejan \& Nield, 2006; Genthon et al., 1997).

In sedimentary rocks occurs the diagenesis, which is a slow chemical, physical or biological change, involving reactions of organic and inorganic species (Rabinowicz et al., 1985). This transformation occurs at moderate temperature and under high pressure, which results in fragmentation of the basin, causing a local change in the permeability and the porosity of the medium (Wood \& Hewett, 1984). The fractures are continuous void spaces with high permeability, where the flow can be reduced by two different processes: precipitation of minerals through the fracture and transport by diffusion of solids from the rocks (Bjørlykke, 1993).

Generally, the ionic activity is the measurement used to determine the apparent concentration of the mineral. When the mineral is dissolved in water, forms an electrolytic solution, because the atoms 


\section{9 a 22 de outubro de 2014 \\ Florianópolis/SC}

which dissociate ions in solution are essentially surrounded by water molecules. Therefore, the concentration of the solute depends on these interactions, known as inter-ionic forces (Kühn, 2004). The dissolution can refer to partial or complete changes in the composition of a mineral due to solubilization of the components (Xu \& Pruess, 2001). The direct reaction of a water-rock system results in dissociation of the species and the reverse reaction involves the precipitation (Morse $\&$ Arvidson, 2002).

The solubility of the minerals is greater the greater the influence of carbonic acid; in an acid medium the solubility increases. The solubility is a function of the $\mathrm{pH}$, an important property that influences the equilibrium of the reactions, and can be determined by the concentrations or activities of the hydronium ion (Kehew, 2001).

The most important and abundant minerals of a sedimentary rock are the carbonaceous, among them, the calcite and the dolomite. An important study involving these primary minerals was made by Soler (2003) in which was determined a model and made the simulation of a deposit of radioactive waste in the soil. Moreover, he considered a region (fracture) of high permeability with varying porosity, where occurs solute transport and chemical reactions leading to precipitation of some minerals and dissociation of others.

Due to the interactions that can occur between the fluid and the solid, the phenomenon of heat and mass transfer in a porous medium is more complex than a normal convective problem (Rashad \& El-Kabier, 2010). Therefore, this reactive process requires a methodology developed with a thorough knowledge for its simulation.

The purpose of the present work is to analyze and to simulate the processes of precipitation and dissolution of minerals. It is considered the presence of dissolved species in the flow for the formation of calcite, dolomite and water in the porous medium with variation of the porosity. The properties and parameters are manipulated in order to become similar to the natural environment of rocks.

\section{GOVERNING EQUATIONS AND SOLUTION PROCEDURE}

The model for the process of precipitation and dissolution of minerals is based on the NavierStokes reactive equations: continuity, momentum, energy, pressure, and chemical species. The model is based on the Darcy's law and the Boussinesq approximation. The Boussinesq assumption considers changes in the fluid density due to variations in the fluid temperature and in the species concentration within the fluid. Moreover, consider that the porous medium is homogeneous, and thermally isotropic. The flow is laminar, incompressible and transient. The saturated fluid is in thermodynamic equilibrium with the solid matrix. The porosity and permeability of the medium is variable. The viscous dissipation is negligible and the thermo-physical properties of the porous medium are constant. In addition, the fracture is a region with porosity and permeability higher than the rock, and between the fracture and the rock happens a chemical interaction.

The complete set of equations describing the flow, heat transfer and mass transfer phenomena with the Boussinesq approximation, in dimensionless form, is written as (Francisquetti, 2013): 
Momentum Equation along the $\mathrm{x}$ axis:

$\phi \frac{\partial u}{\partial t}+u \frac{\partial u}{\partial x}+v \frac{\partial u}{\partial y}=-\phi^{2}\left(\frac{\partial P}{\partial x}+\frac{u}{R e D a}\right)+\frac{\phi^{2}}{R e}\left(\frac{\partial^{2} u}{\partial x^{2}}+\frac{\partial^{2} u}{\partial y^{2}}\right)$

Momentum Equation along the y axis:

$\phi \frac{\partial v}{\partial t}+u \frac{\partial v}{\partial x}+v \frac{\partial v}{\partial y}=-\phi^{2}\left(\frac{\partial P}{\partial y}+\frac{v}{R e D a}\right)+\frac{\phi^{2}}{R e}\left(\frac{\partial^{2} v}{\partial x^{2}}+\frac{\partial^{2} v}{\partial y^{2}}\right)-\phi^{2}\left(G r_{T} T+G r_{C_{i}} \sum_{i=1}^{M} C_{i}\right)$

Enthalpy Equation:

$\phi \frac{\partial h}{\partial t}+u \frac{\partial h}{\partial x}+v \frac{\partial h}{\partial y}=\frac{\phi}{R e P r}\left(\frac{\partial^{2} T}{\partial x^{2}}+\frac{\partial^{2} T}{\partial y^{2}}\right) \pm \phi H e \sum_{i=1}^{N} R_{i}$

Concentration of Species Equation:

$\phi \frac{\partial C_{i}}{\partial t}+u \frac{\partial C_{i}}{\partial x}+v \frac{\partial C_{i}}{\partial y}=\frac{\phi}{R e S c}\left(\frac{\partial^{2} C_{i}}{\partial x^{2}}+\frac{\partial^{2} C_{i}}{\partial y^{2}}\right) \pm \phi R_{i}$

The pressure equation is a result of derivative of the momentum equation in the $\mathrm{x}$ direction related to $\mathrm{x}$ and of the momentum equation in the $\mathrm{y}$ direction related to $\mathrm{y}$, resulting in:

$$
\begin{array}{r}
\frac{\partial^{2} P}{\partial x^{2}}+\frac{\partial^{2} P}{\partial y^{2}}=-\frac{1}{\phi} \frac{\partial B}{\partial t}-\frac{1}{\phi}\left(u \frac{\partial B}{\partial x}+v \frac{\partial B}{\partial y}\right)+\frac{1}{R e}\left(\frac{\partial^{2} B}{\partial x^{2}}+\frac{\partial^{2} B}{\partial y^{2}}\right) \\
-\frac{1}{R e D a} B-\left(G r_{T} \frac{\partial T}{\partial y}+G r_{C_{i}} \sum_{i=1}^{N} \frac{\partial C_{i}}{\partial y}\right)
\end{array}
$$

for $B=(\partial u / \partial x+\partial v / \partial y)$ corresponding to the continuity equation.

The geometry has the format of a rectangle of dimensions $6 \times 1$ and the mesh contains $61 \times 21$ equally spaced points in the domain. The boundary conditions and the domain are shown in the Figure 1. The central finite difference scheme is used to discretize the dimensionless equations subject to their initial conditions and boundary conditions: 


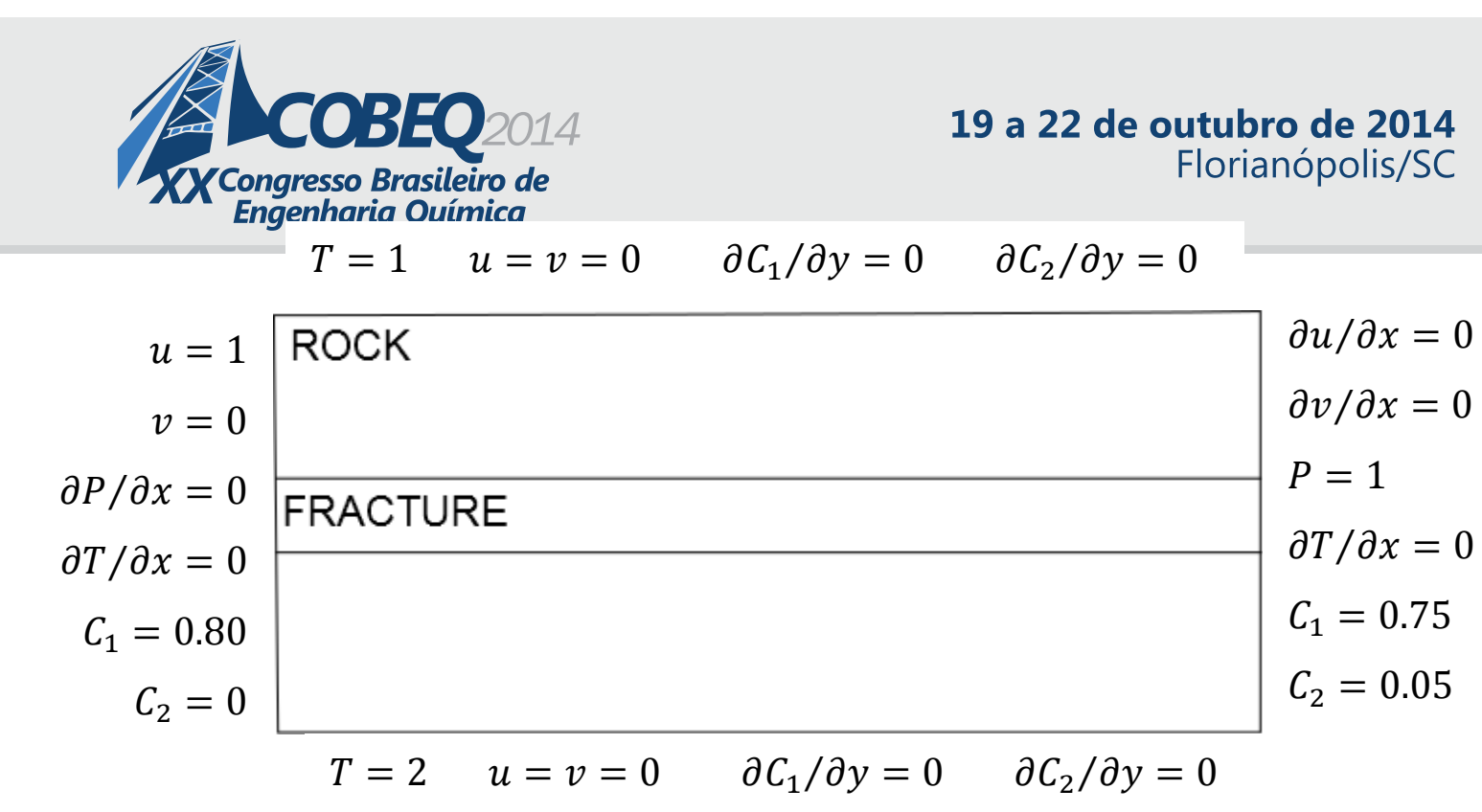

Figure 1 - Domain and boundary conditions of the flow.

The initial conditions for the reactive flow are given by: $u=0, v=0, P=0, T=1$, $C_{1}=0.75, C_{2}=0.05$ and $\phi=0.2$ for all point $(x, y)$. Initially, the concentrations of others species are null and the boundary conditions are of Neumann type.

Below are listed the reactions of precipitation or dissolution of calcite and dolomite in an aqueous medium frequently found in the region of the fracture.

$$
\begin{aligned}
& \mathrm{CaCO}_{3}+\mathrm{H}^{+} \leftrightarrow \mathrm{HCO}_{3}^{-}+\mathrm{Ca}^{2+} \\
& \mathrm{CaMg}\left(\mathrm{CO}_{3}\right)_{2}+2 \mathrm{H}^{+} \leftrightarrow \mathrm{Ca}^{2+}+\mathrm{Mg}^{2+}+2 \mathrm{HCO}_{3}^{-} \\
& \mathrm{H}_{2} \mathrm{O}+\mathrm{CO}_{2(g)} \leftrightarrow \mathrm{H}_{2} \mathrm{CO}_{3}^{*} \\
& \mathrm{H}_{2} \mathrm{CO}_{3}^{*} \leftrightarrow \mathrm{HCO}_{3}^{-}+\mathrm{H}^{+} \\
& \mathrm{HCO}_{3}^{-} \leftrightarrow \mathrm{CO}_{3}^{2-}+\mathrm{H}^{+}
\end{aligned}
$$

where $\mathrm{H}_{2} \mathrm{CO}_{3}{ }^{*}$ represents by convention: $\mathrm{H}_{2} \mathrm{CO}_{3}^{0}+\mathrm{CO}_{2(\mathrm{~g})}$ (Genthon et al., 1997).

The approximation of differential equations gives rise to a series of algebraic equations and in this work is used the Runge-Kutta method for the numerical solutions. The choice of this method is due to the use of a multiple step and its high precision.

The numerical simulations were done using a homemade code developed in Fortran 90. The code runs in a Core i5 3337U, $1.80 \mathrm{GHz}$ and $4 \mathrm{~GB}$ of RAM machine.

\section{RESULTS}

In this section are presented the numerical results for the fluid flow in porous medium with precipitation and dissolution of the primary minerals and with porosity variation in the fracture. Two 
cases are analyzed: first is considered the $\mathrm{pH}=7$ and later the $\mathrm{pH}=13$. The initial concentration of minerals and porosity remain the same in both cases. The results are shown only in the fracture where the variation of minerals is significant, because the fluid flows preferentially through the region of higher permeability.

The Figure 2 shows the graphic that relates the volume, in percentage, occupied by calcite and by dolomite, and the porosity along the fracture for $\mathrm{pH}=7$. The volume of calcite begins to decrease between one and two meters from the inflow, where the mineral dolomite appears. In other words, the dissolution of dolomite occurs when the calcite precipitates. In the first meter from the left of the domain, the dolomite does not appear. The porosity increases until around one meter from the inflow because of the changes that occur in the mineral content. In consequence of this effect the permeability has a significant reduction.

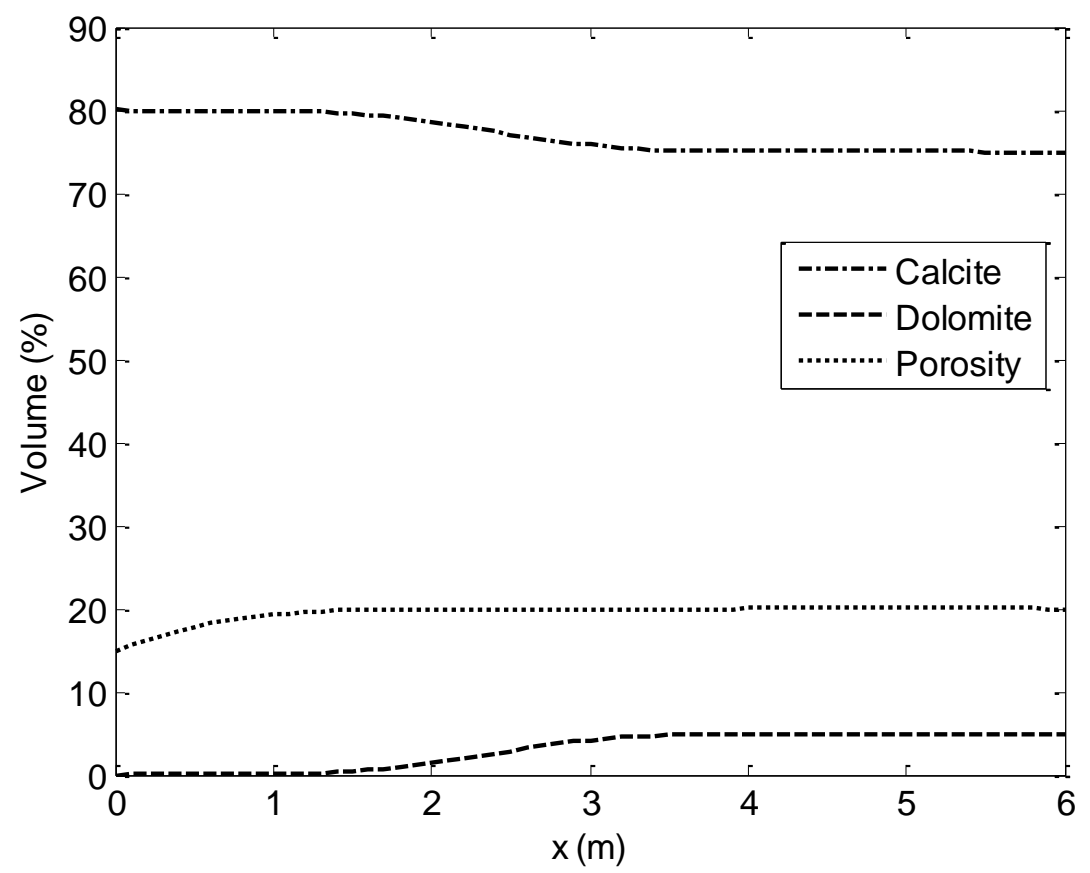

Figure 2 - Volume of mineral versus distance along the fracture for $\mathrm{pH}=7$.

Another test is realized for $\mathrm{pH}=13$ to analyze the influence of this property in the reactive flow. The result of this simulation is demonstrated in the Figure 3. The graph shows that during the first four meters away from the domain entrance did not appear the dolomite. Around of four meters from the inflow the calcite starts to decrease, where the dolomite surge. For $\mathrm{pH}=13$ the change of the two minerals occurs to a larger extent than in the previous case $(\mathrm{pH}=7)$. 


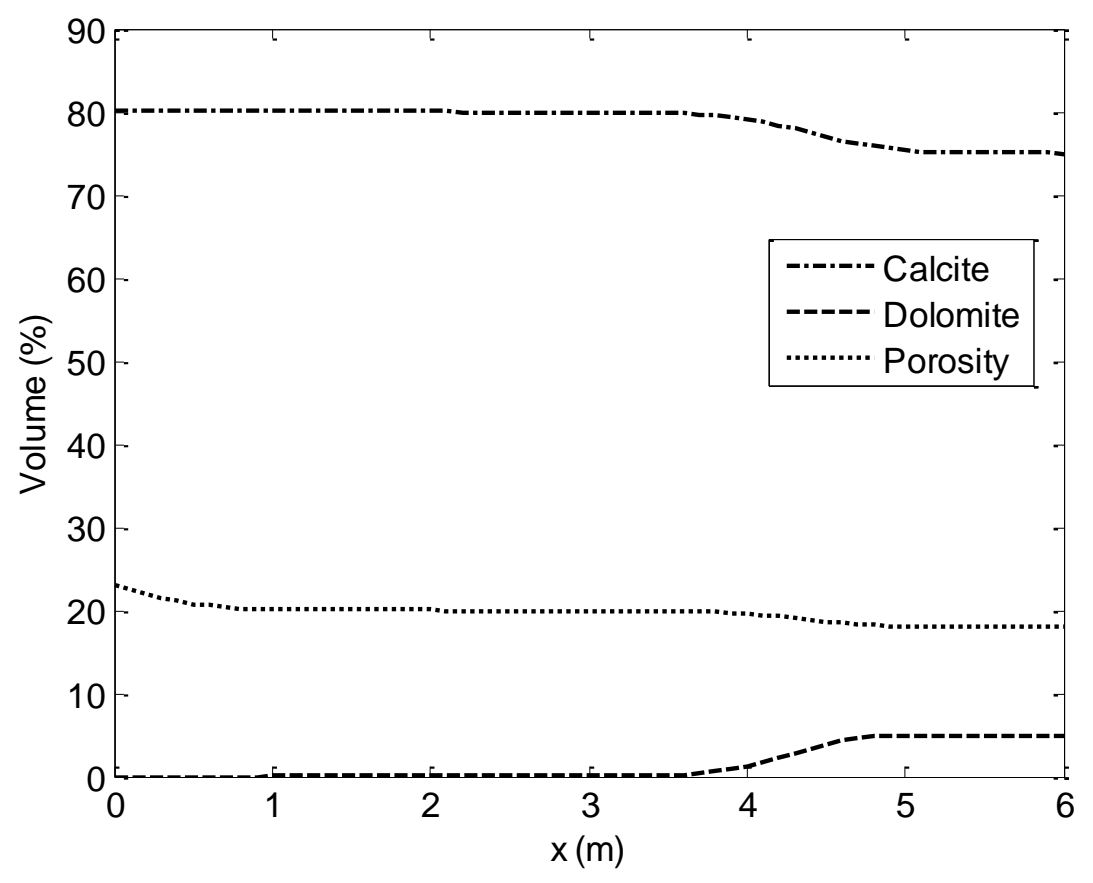

Figure 3 - Volume of mineral versus distance along the fracture for $\mathrm{pH}=13$.

The Figures 2 and 3 are very similar. The most significant difference is in the length of the fracture where the variations of the species occur. For high $\mathrm{pH}$ the dissolution and precipitation of the dolomite and calcite, respectively, happen far away from the inflow. The permeability decreases as the porosity decreases and this reduces the flow velocity.

In both cases the calcite begins with a value of $80 \%$ (in volume) and decreases about $5 \%$. When the dolomite begins to emerge and reaches approximately 5\%. The results of the reactive flow for high $\mathrm{pH}$ found here are similar to the results of Soler (2003).

\section{CONLCUSIONS}

In this work we have developed the model and the simulation of the process of dissolution and precipitation of dolomite and calcite. The model for the reactive flow is two-dimensional and laminar. The set of equations is composed by the continuity, momentum, energy and concentrations of mineral species. The Darcy's law and the Boussinesq approximation are used in the model. The solution procedure is based on the use of the method of central finite differences. The Runge-Kutta method is used to get the numerical solutions.

The domain of simulation is a porous channel with a fracture, where there are variations in porosity and in permeability. Also, in the fracture region, the precipitation or dissolution of minerals occur in an aqueous medium, modeled using five reactions involving ten chemical species. 
Two cases are simulated: for neutral $\mathrm{pH}$ and for high $\mathrm{pH}$. In both cases it was demonstrated that the dissolution of dolomite occurs when the calcite precipitates. However, for higher $\mathrm{pH}$ the alteration of the minerals happen after (around four meters).

Obtained results compare favorably with data found in the literature. Soler (2003) used more minerals in his study, including the secondaries; their results were similar to those for high $\mathrm{pH}$ found in the present work. After a certain time the volume occupied by the calcite reduces, while the dolomite appears along the same position of the fracture.

In summary, obtained results show that in a neutral medium, the mineral calcite is solubilized more easily. In addition, the mineral content changes have caused alteration in the porosity. Therefore, this study contributes to a better understanding of the process that occurs in sedimentary rocks and fluid migration in a porous medium.

\section{NOMENCLATURE}

$C_{1}$ : concentration of calcite.

$C_{2}$ : concentration of dolomite.

Da: Darcy number.

$G r_{T}$ and $G r_{C}$ : Grashof and modified Grashof numbers, respectively.

$h$ : enthalpy.

$H e$ : heat released parameter for the enthalpy equation.

$M$ : number of chemical species.

$N$ : number of reactions.

$P$ : pressure.

Pr: Prandtl number.

$R_{i}$ : reactive source term.

$R e$ : Reynolds number.

Sc: Schmidt number.

$T$ : temperature of the porous medium.

$t$ : time.

$u$ and $v$ : velocity components.

$\phi$ : porosity of the medium.

\section{REFERENCES}

BEJAN, A.; NIELD, D.A. Convection in Porous Media. New York, Springer, $3^{\mathrm{a}}$ ed., 2006.

BJØRLYKKE, K. Fluid flow in sedimentary basins. Sedimentary Geology, 86, p.137-158, 1993. 
FRANCISQUETTI, E. P. Desenvolvimento de um modelo convectivo-difusivo-reativo para a migração de fluidos e combustão em meios porosos. Exame de Qualificação, PPGMAP, UFRGS, Porto Alegre, RS, Brasil, 2013.

GENTHON, P.; SCHOTT, J.; DANDURAND, J. L. Carbonate diagenesis during thermo-convection: Application to secondary porosity generation in clastic reservoirs. Chem. Geology, 142, p. 4161, 1997.

KEHEW, A. E. Applied chemical hydrogeology. Prentice Hall, 2001.

KÜHN, M. Reactive Flow Modeling of Hydrothermal Systems. Lecture Notes in Earth Sciences. Springer, 2004.

MORSE, J. W.; ARVIDSON, R. S. The dissolution kinetics of major sedimentary carbonate minerals. Earth-Science Reviews, 58, p. 51-84, 2002.

RABINOWICZ M.; DANDURAND, J. L.; JAKUBOWSKI, M.; SCHOTT, J.; CASSAN, J. P. Convection in a north sea oil reservoir: Inferences on diagenesis and hydrocarbon migration. Earth and Planetary Science Letters, 74, p. 387-404, 1985.

RASHAD, A.M.; EL-KABEIR, S.M.M. Heat and mass transfer in transient flow by mixed convection boundary layer over a stretching sheet embedded in a porous medium with chemically reactive species. J. of Porous Media, 13, p. 75-85, 2010.

SOLER, J.M. Reactive transport modeling of the interaction between a high-pH plume and a fractured marl: the case of Wellenberg. Applied Geochemistry,18, p. 1555-1571, 2003.

WOOD, J. R.; HEWETT, T.A. Reservoir diagenesis and convective fluid flow. Clastic diagenesis: AAPG Memoir, 37, p. 99-110, 1984.

XU, T.; PRUESS, K. Modeling multiphase non-isothermal fluid flow and reactive geochemical transport in variably saturated fractured rocks: 1. Methodology. American J. of Science, 301, p. 16-33, 2001. 